\title{
Low Serum Levels of Myeloid Progenitor Inhibitory Factor-1 Predict Good Response to Methotrexate in Rheumatoid Arthritis
}

\author{
Varun Dhir, ${ }^{1}$ Amit Sandhu, ${ }^{1}$ Nidhi Gupta, ${ }^{1}$ Veena Dhawan, \\ Shefali Sharma, ${ }^{1}$ and Aman Sharma ${ }^{1}$ \\ ${ }^{1}$ Department of Internal Medicine (Rheumatology Unit), Post Graduate Institute of Medical Education and Research, \\ Chandigarh 160012, India \\ ${ }^{2}$ Department of Experimental Medicine and Biotechnology, Post Graduate Institute of Medical Education and Research, \\ Chandigarh 160012, India
}

Correspondence should be addressed to Varun Dhir; varundhir@gmail.com

Received 8 October 2013; Accepted 27 November 2013

Academic Editors: D. Frommhold, C. Patruno, and B. Rozman

Copyright ( 2013 Varun Dhir et al. This is an open access article distributed under the Creative Commons Attribution License, which permits unrestricted use, distribution, and reproduction in any medium, provided the original work is properly cited.

Background. Although the benchmark in the treatment of rheumatoid arthritis remains methotrexate, only $70 \%$ of patients respond. Thus, there is a need for predictive biomarkers. This study planned to evaluate serum levels of myeloid progenitor inhibitory factor-1 (MPIF-1) and monocyte chemoattractant protein 2 (MCP-2) - as biomarkers. Methods. Patients with rheumatoid arthritis (RA) having high disease activity (DAS28-3v $\geq 5.1$ ) were treated with oral methotrexate (MTX) for 12 weeks. Disease activity was measured by DAS28-3v (Modified Disease Activity Score 3 variables). Serum samples were stored at baseline and 12 weeks. Results. This study included 46 patients $(\mathrm{F}: \mathrm{M}=35: 11)$ having mean $( \pm \mathrm{SD})$ age of $42.6 \pm 11.3 \mathrm{yrs}$, disease duration of $4.7 \pm 4.5 \mathrm{yrs}$, and DAS28-3v of 6.1 \pm 0.8. Serum MPIF1 was elevated in patients compared to controls $(1636.7 \pm 1009.7,441.2 \pm 173.8 \mathrm{pg} / \mathrm{mL}, P<0.001)$, but there was no difference in MCP2 levels $(31.4 \pm 11.9,33.8 \pm 24.0 \mathrm{pg} / \mathrm{mL})$. Baseline MPIF-1 level was lower in good responders $(\triangle \mathrm{DAS} 28-3 \mathrm{v} \geq 1.2, N=9)$ compared to poor responders $(\triangle \mathrm{DAS} 28-3 \mathrm{v}<0.6, N=27)(1171.0 \pm 670.8,1816.7 \pm 1154.1 \mathrm{pg} / \mathrm{mL}$, $P=0.05$ ). On ROC analysis, baseline MPIF1 performed reasonably to predict good response; that is, $\Delta \mathrm{DAS} 28-3 \mathrm{v} \geq 1.2$ (AUC 0.68, 95\% CI 0.50-0.87). Conclusions. Lower baseline MPIF1 level predicted a good response to methotrexate at 12 weeks.

\section{Introduction}

Rheumatoid arthritis is an autoimmune chronic inflammatory disease predominantly affecting the joints [1]. There is a recent emphasis on a "treat to target" strategy, with regular monitoring of disease activity and quick adjustments of drugs [2]. Although joint assessment remains the gold standard for disease activity, biomarkers may come to play a complementary role [3]. In the treatment of RA, the benchmark drug remains methotrexate. However, it is effective in only $70 \%$ of patients, and an excellent response is seen in only $30 \%$ of patients. A common therapeutic strategy is to start with methotrexate, and patients who do not respond to methotrexate are subsequently shifted to other drugs or combinations (other DMARDs or biologicals). However, waiting for response to methotrexate may delay institution of other effective therapies in nonresponders and contribute to joint damage. Thus, there is a need to identify nonresponders to methotrexate upfront to institute other therapies [4] hence the need for activity and predictive biomarkers [5].

Chemokines are small proteins involved in chemoattraction of a variety of cells to site of inflammation, being important in the pathogenesis of RA and may serve as biomarkers [6]. MCP-2 (monocytes chemoattractant protein 2) or CCL8 (chemokine C-C motif Ligand 8) is a chemokine involved in chemoattraction of monocytes, T cells, and NK cells $[7,8]$. MPIF-1 (myeloid progenitor inhibitory factor-1) or CCL23 (chemokine C-C Ligand 23) is involved in chemoattraction of resting T cells and monocytes $[9,10]$. Both of these have been shown to be upregulated in a previous study in RA and are potential biomarkers [11]. We wanted to look at their value as biomarkers in a prospective cohort of rheumatoid arthritis patients treated with methotrexate. 


\section{Material and Methods}

This study was conducted from July 2011 to March 2012 at a university hospital after approval from the Institutional Ethics Committee. Written informed consent was taken from all subjects.

2.1. Study Design. This was a prospective study over 12 weeks, which included rheumatoid arthritis patients taking part in another clinical trial which compared starting with $7.5 \mathrm{mg}$ versus $15 \mathrm{mg}$ per week of methotrexate (Trial Registry no. NCT01404429). In this study only those patients who started with $15 \mathrm{mg}$ methotrexate were included after consent.

2.2. Subjects. Inclusion criteria were (a) fulfillment of the 1987 American College of Rheumatology (ACR) criteria for rheumatoid arthritis [12], (b) 18 to 65 years of age, (c) having high disease activity (DAS28-3v $\geq 5.1$ ), (d) not taking methotrexate for $\geq 2$ months, (e) permitted to be on corticosteroids if dose is stable for $\geq 1$ week and dose of prednisolone equivalent was $\leq 10 \mathrm{mg} /$ day, and (f) permitted to be on other disease modifying antirheumatic drugs (DMARDs) like sulfasalazine, leflunomide, and hydroxychloroquine, if dosages are stable for $\geq 2$ weeks. Standard exclusion criteria for methotrexate were followed. Patients were excluded if they were/ had (a) breast-feeding or pregnant (in women), (b) liver disease, (c) renal disease, (d) active infections or (e) hepatitis $\mathrm{B}$ or $\mathrm{C}$ positive. In addition, 16 age- and gender-matched controls were enrolled from attendants of patients/staff after consent.

2.3. Intervention. Patients were started on $15 \mathrm{mg}$ per week dose of methotrexate, which was escalated by $2.5 \mathrm{mg}$ biweekly (maximum $25 \mathrm{mg}$ ) till 12 weeks. In addition, folate supplementation ( $5 \mathrm{mg}$ twice a week $=10 \mathrm{mg} /$ week) was given. Patients were monitored 4 weekly with complete blood counts and liver function tests, and methotrexate was withheld/not increased in case of cytopenias or transaminitis.

2.4. Clinical Assessment. The modified Disease Activity Score using 3 variables (DAS28-3v) was calculated to measure the disease activity [13]. This was calculated using the formula: DAS28-3v $=\left[0.56^{*} \sqrt{ }\right.$ (tender joints $)+0.28^{*} \sqrt{ }$ (swollen joints $)$ $\left.+0.70^{*} \operatorname{Ln}(\mathrm{ESR})\right]^{*} 1.08+0.16$, where joint count was done on 28 joints and ESR was measured using Westegren method (first hour). Change in disease activity ( $\triangle \mathrm{DAS} 28-3)$ was calculated as the difference in DAS28-3 at baseline (0 week) "minus" final (12 weeks). Patients were stratified into 3 categories of response based on change in disease activity ( $\triangle \mathrm{DAS} 28-3)$. The three categories were good, moderate, and poor responsers, defined as $\triangle \mathrm{DAS} 28-3 \geq 1.2,0.6-1.2$, and $<0.6$, respectively. In addition, the functional status of the patients was measured using Indian health assessment questionnaire at baseline and 12 weeks [14].

2.5. Laboratory Tests. Blood sample was obtained at baseline and 12 weeks; serum was separated and stored at $-80^{\circ} \mathrm{C}$. In addition, serum of controls was also stored. ELISA for MPIF1 and MCP-2 (RayBio) was done on the stored samples after completion of original study. Minimum detectable limits of MPIF- 1 and MCP- 2 were $7 \mathrm{pg} / \mathrm{mL}$ and $1.5 \mathrm{pg} / \mathrm{mL}$, respectively.

2.6. Statistical Analysis. Student's $t$ test was used to compare the chemokine levels between patients and controls. Pearson's correlation was used to look at the correlation between chemokine levels and disease activity. In addition, multivariable linear regression and receiver operator curve (ROC) analysis were done. Analysis was done using SPSS v15 and GraphPad Prism (version 5).

\section{Results}

This study included 46 patients ( $\mathrm{F}: \mathrm{M}=35: 11$ ) with rheumatoid arthritis. Their mean age was $42.6 \pm 11.3$ yrs and duration of disease was $4.7 \pm 4.5$ years. Baseline disease activity (DAS28-3v) was $6.1 \pm 0.8$, HAQ score was $1.3 \pm 0.7$, and 30 (65\%) were rheumatoid factor positive. At 12 weeks, the mean dose of methotrexate reached was $24.3 \pm 2.0 \mathrm{mg} /$ week and mean $( \pm S D)$ change in DAS28-3v and HAQ was $0.5 \pm 0.6$ and $0.3 \pm 0.5$, respectively.

Baseline level of MPIF-1 was elevated in patients compared to controls $(1636.7 \pm 1009.7,441.2 \pm 173.8, P<0.001)$. However, there was no difference in the MCP-2 level (33.8 \pm 24.0, $31.4 \pm 11.9, P=\mathrm{ns}$ ) (Figure 1). On stratifying patients by response to MTX as per $\triangle \mathrm{DAS} 28-3 \mathrm{v}$, among different baseline characteristics, only MPIF-1 level was significantly different across groups (Table 1). Also, baseline MPIF-1 had a significant though modest correlation with $\triangle \mathrm{DAS} 28-3 \mathrm{v}$ $(P=0.04)$ (Figure 2$)$. On multivariate linear regression, only baseline MPIF-1 levels and disease duration were significant predictors of change in DAS28-3v $\left(r^{2}=0.28\right)$. On ROC analysis, baseline MPIF-1 had area under curve of $0.68(95 \%$ CI $0.50-0.87$ ) and a level of $<946 \mathrm{pg} / \mathrm{mL}$ was found to have the best predictive value with a sensitivity and specificity of 55.6 and $81 \%$ to predict good response to MTX.

Although baseline MPIF-1 was elevated and predicted response, it did not significantly change after 12 weeks (1557.4 $\pm 1155.4, P=\mathrm{ns})$. However, MCP-2 level increased at 12 weeks $(55.0 \pm 19.2, P<0.001)$. There was a lack of correlation between change in DAS28 $(\triangle \mathrm{DAS} 28-3 \mathrm{v})$ and change in MPIF-1 levels $(\triangle \mathrm{MPIF}-1)(r=-0.24, P=0.1)$ or MCP-2 levels $(\triangle \mathrm{MCP}-2)(r=-0.144, P=0.35)$.

\section{Discussion}

This study found serum level of MPIF-1 to be raised in rheumatoid arthritis patients compared to controls. A lower level of MPIF-1 at baseline predicted better response to methotrexate over 12 weeks.

This study found MPIF-1 (myeloid progenitor inhibitory factor-1) levels to be raised 4-fold in serum of rheumatoid arthritis (RA) patients compared to controls. This is similar to a previous study that found a 1.3-fold higher level in plasma of patients [11]. Higher levels are not surprising, in view of the fact that MPIF-1 is involved in chemoattraction of resting $\mathrm{T}$ cells and monocytes $[9,10]$. Also, its cognate receptor 
TABLE 1: Baseline characteristics of the 3 categories of change in DAS28-3v.

\begin{tabular}{|c|c|c|c|}
\hline \multirow{2}{*}{ Baseline characteristics ((mean \pm SD), unless specified $)$} & \multicolumn{3}{|c|}{ Change in DAS28-3v (0-12 weeks) } \\
\hline & $\geq 1.2(N=9)$ & 0.6 to $1.2(N=10)$ & $<0.6(N=27)$ \\
\hline MPIF-1 (pg/mL) & $1171.0 \pm 670.8^{*}$ & $1570.0 \pm 728.3$ & $1816.7 \pm 1154.1$ \\
\hline MCP-2 (pg/mL) & $29.5 \pm 18.3$ & $29.2 \pm 22.2$ & $36.7 \pm 27.2$ \\
\hline DAS28-3v & $5.9 \pm 0.9$ & $6.3 \pm 0.8$ & $6.1 \pm 0.7$ \\
\hline ESR (mm first hour) & $57.2 \pm 31.2$ & $77 \pm 34.9$ & $60.5 \pm 31.3$ \\
\hline Duration of disease (years) & $3.8 \pm 3.9$ & $4.1 \pm 3$ & $6 \pm 5.1$ \\
\hline Age (years) & $43.7 \pm 10.4$ & $42.3 \pm 8.2$ & $42.4 \pm 12.8$ \\
\hline RF positive $N(\%)$ & $8(89)$ & $6(60)$ & $16(59)$ \\
\hline Female gender $N(\%)$ & $5(56)$ & $9(90)$ & $21(78)$ \\
\hline
\end{tabular}

${ }^{*} P=0.05$ compared to DAS28-3v $<0.6$.

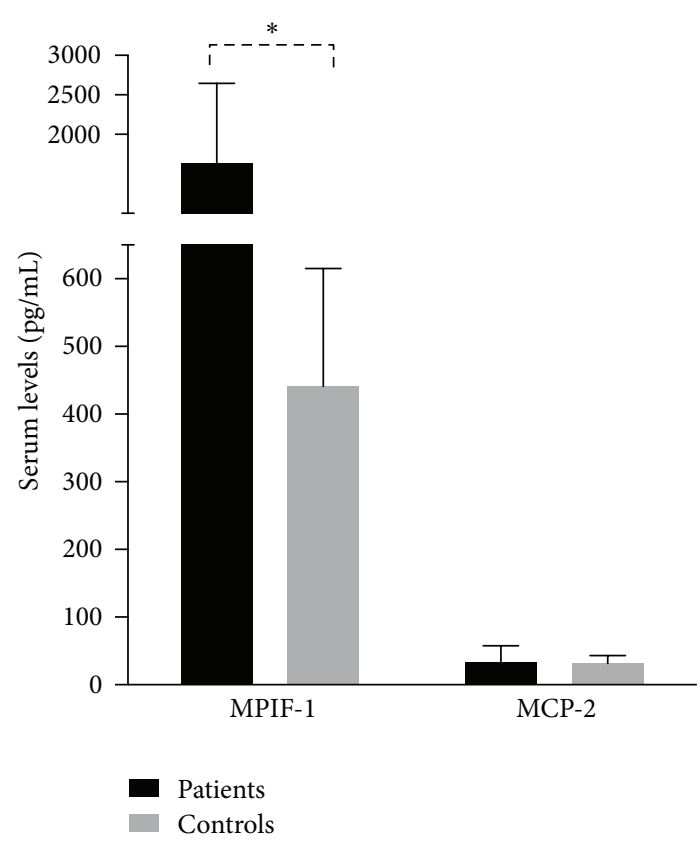

FIgURE 1: Baseline values of biomarkers $\left({ }^{*} P<0.001\right)$.

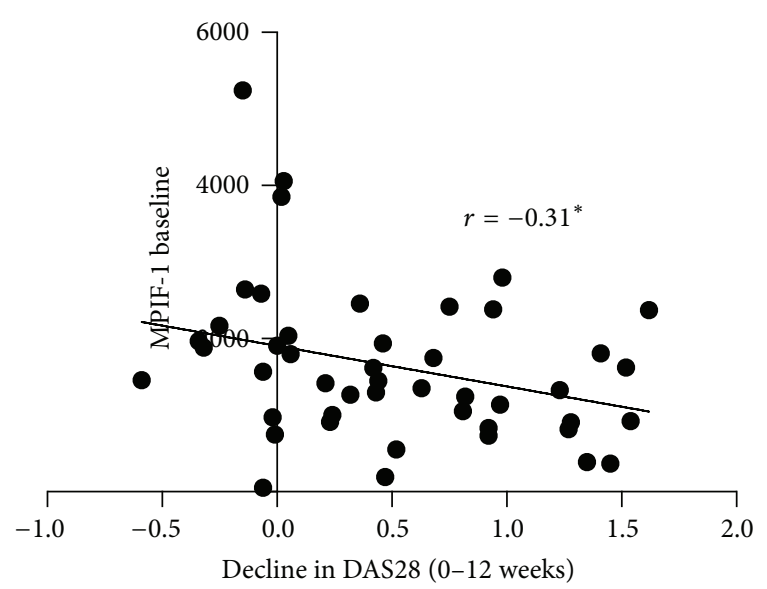

FIGURE 2: Correlation between baseline MPIF-1 and change in DAS28-3v ( $\left.{ }^{*} P=0.04\right)$.
(CCR1) has been shown to be upregulated in synovial tissue of patients with rheumatoid arthritis [15].

Lower MPIF-1 levels at baseline were associated with better response to methotrexate at 12 weeks. Indeed, MPIF1 was modestly accurate on ROC analysis (AUC $=0.68$ ) in identifying patients with good response $(\triangle \mathrm{DAS} 28 \geq 1.2)$. Although it had modest predictive ability, as a comparison, a recent prediction model to predict methotrexate response in JIA, using SNPs in 4 genes and ESR, could only have an AUC of 0.65 [16]. This is the first study to look at MPIF-1 as a predictor for methotrexate response. In general, there is a paucity of biomarkers to predict response to methotrexate, and a systematic review found that predictive criteria were mainly clinical including male gender, low disease activity at baseline, DMARD naivety, negative rheumatoid factor, and being nonsmokers. However, none of these were found to have a high predictive value [17]. Indeed, these clinical parameters are probably markers of severe disease rather than of response to methotrexate [18]. Another study also reiterated that clinical characteristics were poor predictors of methotrexate response [19]. In contrast to our results of MPIF-1 as a predictive biomarker, we did not find it to be a useful biomarker for disease activity and found no change in levels on methotrexate treatment. A previous study also did not find any change in levels after 1 week of anti-TNF treatment, although they did find higher levels in active patients [11].

This study did not find any difference in MCP-2 levels between patients and controls, similar to a previous study [11]. However, MCP-2 has been found to be overexpressed in synovial biopsy specimens, [15] and its transcripts are upregulated on TLR2 stimulation of cultured synovial fibroblasts [20]. Thus, circulating MCP-2 levels may not reflect local synovial tissue levels. This study found an increase of MCP2 levels posttreatment of rheumatoid arthritis (with decline in disease activity). A previous study, on the contrary, found higher levels in active patients versus quiescent patients. This difference can be partly explained by differences in design.

The strength of our study is the longitudinal design. Important drawbacks are the limited number of patients and the short followup of only 12 weeks. This short duration was chosen, as 12 weeks is fast emerging as a decision point as per both guidelines and major trials, when other drugs (including biologicals) are added in the face of inadequate response to 
MTX [21-23]. We preferred to use DAS28-3v score omitting the patient assessment on visual analog scale, as our patients poorly understand the concept of a visual analog scale.

To conclude, this study found that MPIF-1 may be a useful biomarker for predicting response to methotrexate in rheumatoid arthritis, with lower levels baseline predicting higher change in DAS28-3v (better response).

\section{Acknowledgments}

This project was supported by a grant from the Indian Rheumatology Association to Dr. Varun Dhir. Methotrexate which was administered to the patients was gifted by Zydus Synovia, Ahmedabad.

\section{References}

[1] D. L. Scott, F. Wolfe, and T. W. J. Huizinga, "Rheumatoid arthritis," The Lancet, vol. 376, no. 9746, pp. 1094-1108, 2010.

[2] J. S. Smolen, D. Aletaha, J. W. Bijlsma et al., "Treating rheumatoid arthritis to target: recommendations of an international task force," Annals of the Rheumatic Diseases, vol. 69, no. 4, pp. 631-637, 2010.

[3] T. Sokka and T. Pincus, "Quantitative joint assessment in rheumatoid arthritis," Clinical and Experimental Rheumatology, vol. 23, no. 5, pp. S58-S62, 2005.

[4] T. Pincus, Y. Yazici, T. Sokka, D. Aletaha, and J. S. Smolen, "Methotrexate as the "anchor drug" for the treatment of early rheumatoid arthritis," Clinical and Experimental Rheumatology, vol. 21, no. 5, pp. S179-S185, 2003.

[5] P. J. Mease, "The potential roles for novel biomarkers in rheumatoid arthritis assessment," Clinical and Experimental Rheumatology, vol. 29, no. 3, pp. 567-574, 2011.

[6] A. D. Luster, "Chemokines-chemotactic cytokines that mediate inflammation," The New England Journal of Medicine, vol. 338, no. 7, pp. 436-445, 1998.

[7] P. Proost, A. Wuyts, and J. van Damme, "Human monocyte chemotactic proteins-2 and -3: structural and functional comparison with MCP-1," Journal of Leukocyte Biology, vol. 59, no. 1, pp. 67-74, 1996.

[8] W. Gong, O. M. Z. Howard, J. A. Turpin et al., "Monocyte chemotactic protein-2 activates CCR5 and blocks CD4/CCR5mediated HIV-1 entry/replication," The Journal of Biological Chemistry, vol. 273, no. 8, pp. 4289-4292, 1998.

[9] V. P. Patel, B. L. Kreider, Y. Li et al., "Molecular and functional characterization of two novel human C-C chemokines as inhibitors of two distinct classes of myeloid progenitors," Journal of Experimental Medicine, vol. 185, no. 7, pp. 1163-1172, 1997.

[10] R. D. Berahovich, Z. Miao, Y. Wang, B. Premack, M. C. Howard, and T. J. Schall, "Proteolytic activation of alternative CCR1 ligands in inflammation," Journal of Immunology, vol. 174, no. 11, pp. 7341-7351, 2005.

[11] I. Rioja, F. J. Hughes, C. H. Sharp et al., "Potential novel biomarkers of disease activity in rheumatoid arthritis patients: CXCL13, CCL23, transforming growth factor $\alpha$, tumor necrosis factor receptor superfamily member 9 , and macrophage colonystimulating factor," Arthritis and Rheumatism, vol. 58, no. 8, pp. 2257-2267, 2008.
[12] F. C. Arnett, S. M. Edworthy, D. A. Bloch et al., "The American rheumatism association 1987 revised criteria for the classification of rheumatoid arthritis," Arthritis and Rheumatism, vol. 31, no. 3, pp. 315-324, 1988.

[13] DAS-SCORE.NL, 2011, http://www.das-score.nl/das28/en/.

[14] A. Kumar, A. N. Malaviya, A. Pandhi, and R. Singh, "Validation of an Indian version of the health assessment questionnaire in patients with rheumatoid arthritis," Rheumatology, vol. 41, no. 12, pp. 1457-1459, 2002.

[15] J. J. Haringman, T. J. M. Smeets, P. Reinders-Blankert, and P. P. Tak, "Chemokine and chemokine receptor expression in paired peripheral blood mononuclear cells and synovial tissue of patients with rheumatoid arthritis, osteoarthritis, and reactive arthritis," Annals of the Rheumatic Diseases, vol. 65, no. 3, pp. 294-300, 2006.

[16] M. Bulatović, M. W. Heijstek, E. H. P. van Dijkhuizen, N. M. Wulffraat, S. M. F. Pluijm, and R. de Jonge, "Prediction of clinical non-response to methotrexate treatment in juvenile idiopathic arthritis," Annals of the Rheumatic Diseases, vol. 71, no. 9, pp. 1484-1489, 2012.

[17] J. Drouin, B. Haraoui, and 3e Initiative Group, "Predictors of clinical response and radiographic progression in patients with rheumatoid arthritis treated with methotrexate monotherapy," Journal of Rheumatology, vol. 37, no. 7, pp. 1405-1410, 2010.

[18] W. Katchamart, S. Johnson, H. L. Lin, V. Phumethum, C. Salliot, and C. Bombardier, "Predictors for remission in rheumatoid arthritis patients: a systematic review," Arthritis Care and Research, vol. 62, no. 8, pp. 1128-1143, 2010.

[19] S. L. Hider, A. J. Silman, W. Thomson, M. Lunt, D. Bunn, and D. P. M. Symmons, "Can clinical factors at presentation be used to predict outcome of treatment with methotrexate in patients with early inflammatory polyarthritis?" Annals of the Rheumatic Diseases, vol. 68, no. 1, pp. 57-62, 2009.

[20] M. Pierer, J. Rethage, R. Seibl et al., "Chemokine secretion of rheumatoid arthritis synovial fibroblasts stimulated by toll-like receptor 2 ligands," Journal of Immunology, vol. 172, no. 2, pp. 1256-1265, 2004.

[21] J. S. Smolen, R. Landewé, F. C. Breedveld et al., "EULAR recommendations for the management of rheumatoid arthritis with synthetic and biological disease-modifying antirheumatic drugs," Annals of the Rheumatic Diseases, vol. 69, no. 6, pp. 964975, 2010.

[22] J. A. Singh, D. E. Furst, A. Bharat et al., "2012 update of the 2008 American college of rheumatology recommendations for the use of disease-modifying antirheumatic drugs and biologic agents in the treatment of rheumatoid arthritis," Arthritis Care and Research, vol. 64, no. 5, pp. 635-639, 2012.

[23] R. van Vollenhoven, S. Ernestam, P. Geborek et al., "Addition of infliximab compared with addition of sulfasalazine and hydroxychloroquine to methotrexate in patients with early rheumatoid arthritis (Swefot trial): 1-year results of a randomised trial," The Lancet, vol. 374, no. 9688, pp. 459-466, 2009. 


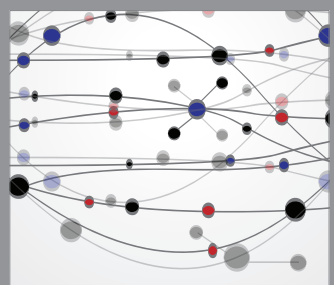

The Scientific World Journal
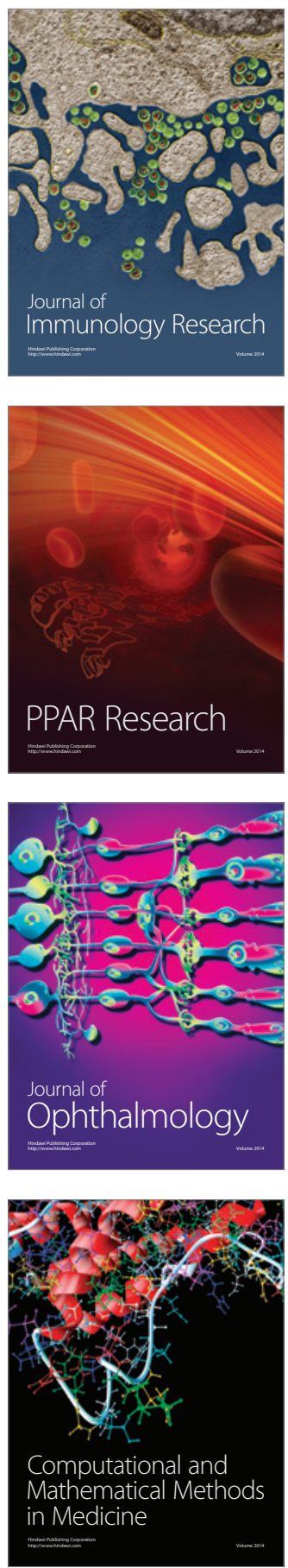

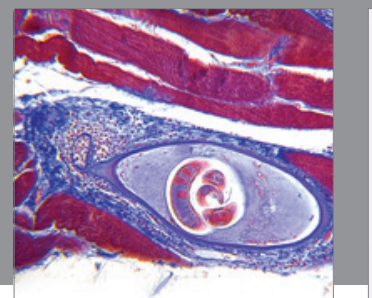

Gastroenterology

Research and Practice
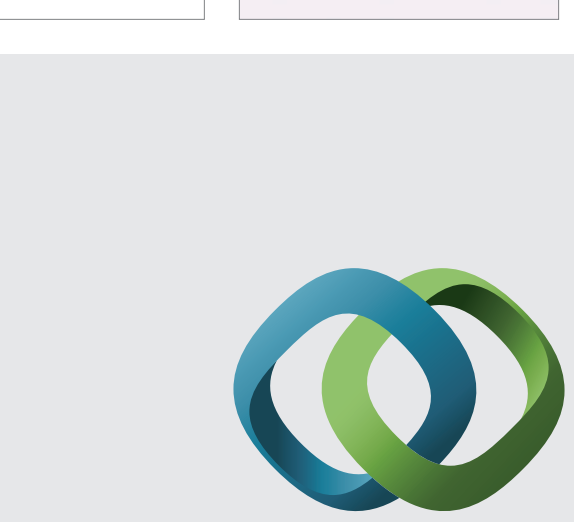

\section{Hindawi}

Submit your manuscripts at

http://www.hindawi.com
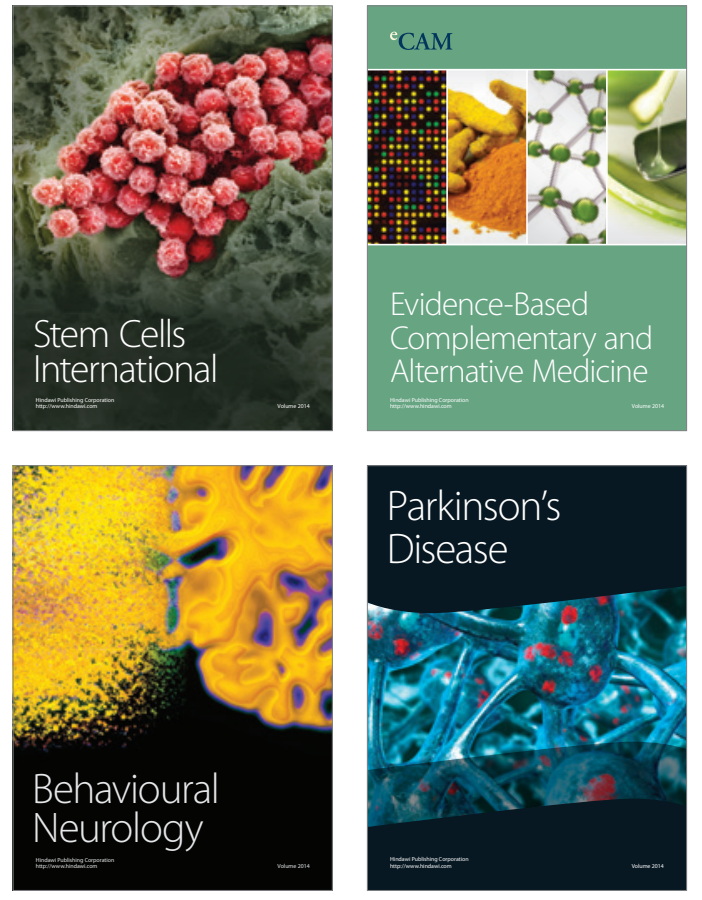
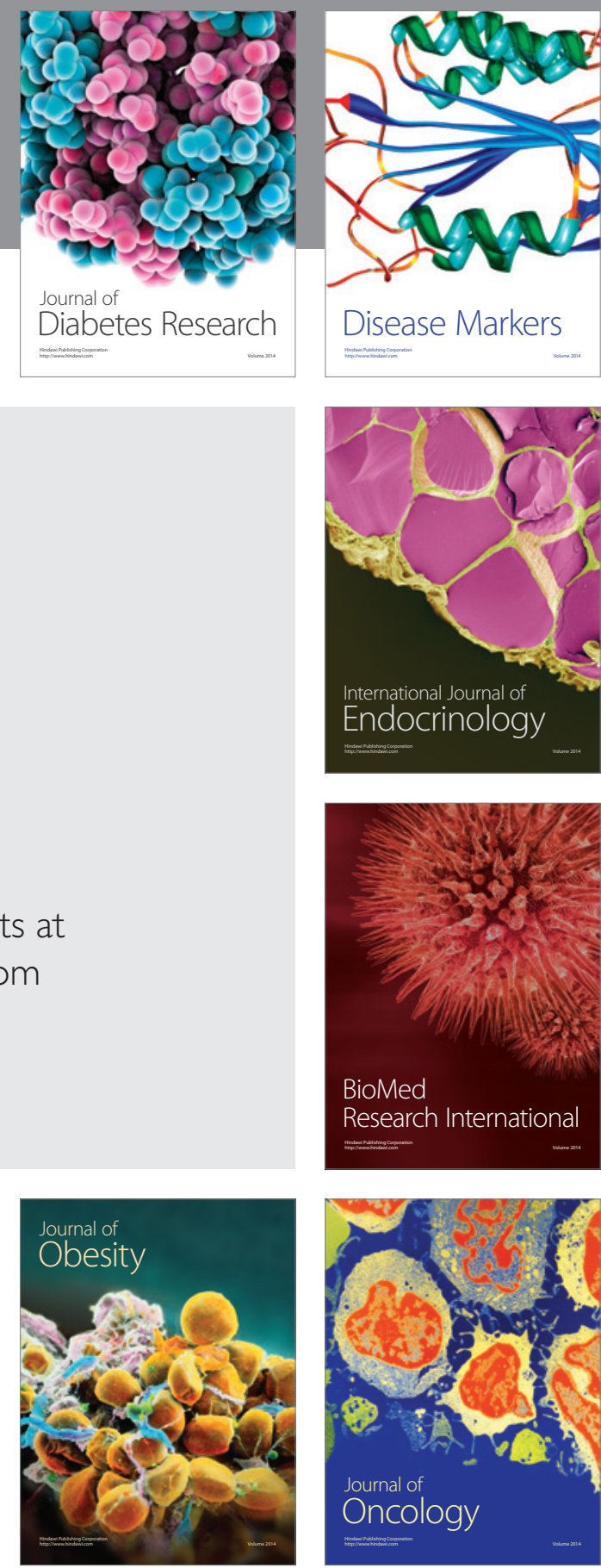

Disease Markers
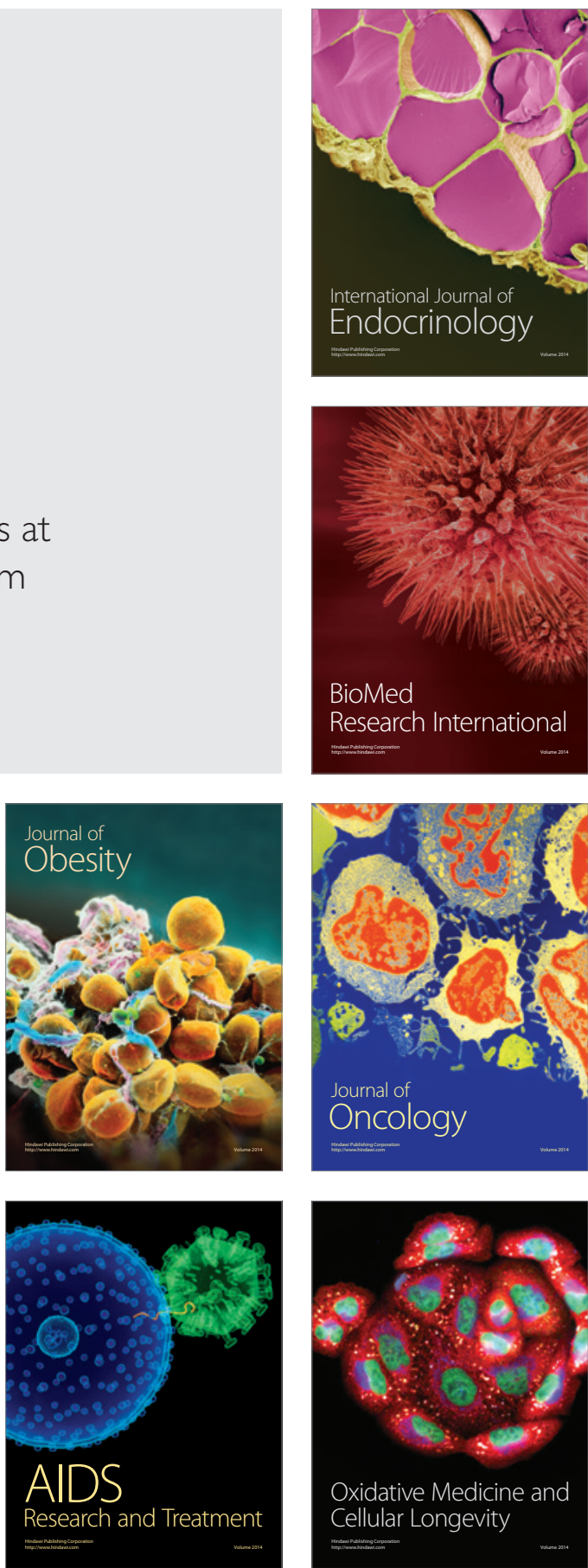